\title{
Multifocal Spontaneous Intracerebral Hemorrhage about a Case and Review of the Literature
}

\author{
Prince Eliot Galieni Sounga Bandzouzi ${ }^{1,2 *}$, Hugues Brieux Ekouele Mbaki ${ }^{2,3}$, \\ Dina Happhia Motoula Latou ${ }^{2,4}$, Ghislain Armel Mpandzou ${ }^{2,4}$, Josue Diatewa ${ }^{2,4}$, \\ Aimé Kaoudi', Nelly Mbourou Diouf6, Frida Ninelle Awam Amioth ${ }^{7}$, Vital Ebelebe ${ }^{1,2}$, \\ Godefroy Charles Koubemba1, Paul Macaire Osou-Nguiet'2,4 \\ ${ }^{1}$ Department of Neurology, Loandjili General Hospital, Pointe-Noire, Congo \\ ${ }^{2}$ Faculty of Health Sciences, Marien Ngouabi University, Brazzaville, Congo \\ ${ }^{3}$ Department of Neurosurgery, University Hospital of Brazzaville, Brazzaville, Congo \\ ${ }^{4}$ Department of Neurology, University Hospital of Brazzaville, Brazzaville, Congo \\ ${ }^{5}$ Department of Neurosurgery, Loandjili General Hospital, Pointe-Noire, Congo \\ ${ }^{6}$ Department of Neurology, University Hospital of Libreville, Libreville, Gabon \\ ${ }^{7}$ Department of Radiology, Loandjili General Hospital, Pointe-Noire, Congo \\ Email: *eliotprince2002@yahoo.fr
}

How to cite this paper: Sounga Bandzouzi, P.E.G., Mbaki, H.B.E., Latou, D.H.M., Mpandzou, G.A., Diatewa, J., Kaoudi, A., Diouf, N.M., Amioth, F.N.A., Ebelebe, V., Koubemba, G.C. and Osou-Nguiet, P.M. (2020) Multifocal Spontaneous Intracerebral $\mathrm{He}$ morrhage about a Case and Review of the Literature. Neuroscience \& Medicine, 11, 12-19.

https://doi.org/10.4236/nm.2020.111002

Received: December 23, 2019

Accepted: January 28, 2020

Published: January 31, 2020

Copyright $\odot 2020$ by author(s) and Scientific Research Publishing Inc. This work is licensed under the Creative Commons Attribution-NonCommercial International License (CC BY-NC 4.0). http://creativecommons.org/licenses/by-nc/4.0/ (c) (i) (8) Open Access

\begin{abstract}
We describe the case of a spontaneous multifocal intracerebral hemorrhage in a Congolese subject presenting no risk factor. $\mathrm{He}$ is a 32 -year-old subject with no particular history admitted for seizures in which the cerebral scanner has revealed spontaneous multifocal intracerebral hemorrhages. He only received medical treatment. It remains a very rare entity. The location of the hemato$\mathrm{ma}$ is variable and is usually located in the basal ganglia due to chronic hypertension.
\end{abstract}

\section{Keywords}

Intracerebral Hemorrhage, Spontaneous Multifocal, Seizures

\section{Introduction}

Intracerebral hemorrhage represents $8 \%$ to $30 \%$ of all strokes in the West [1] [2], but $28 \%$ to $60 \%$ in Africa [3] [4]. Multifocal spontaneous intracerebral hemorrhage is a rare phenomenon [5] [6] and is a separate entity from focal intracerebral hemorrhage. The pathophysiology of spontaneous multifocal intracerebral hemorrhages has not been elucidated [6]. However, several contributing factors 
have been described in the literature, namely: hypertension, multiple micro-bleeding, by lipohyalinosis, cerebral angiopathy, vasculitis, deep cerebral venous thrombosis, oral anticoagulants, cerebral hemorrhagic infarctions and neoplasm [1] [5] [6] [7]. The multifocal nature of the hemorrhage makes management more difficult and correlates this entity with increased mortality [7] [8]. There is no consensus on the best method for managing these lesions. Medical and surgical management strategies can be considered for these patients. Thus, we report an observation of spontaneous multifocal intracerebral hemorrhage in a young Congolese subject in Pointe-Noire.

\section{Cases Reports}

A 32-year-old Mr TM without any particular antecedents admitted for generalized tonic-clonic seizures of generalized duration of 5 minutes with loosening sphincter, bite of the lateral edge of the tongue in a context of headaches in intense helmet. Type of hammer strike associated with vomiting-type digestive disorders at the rate of two discharges. The clinical examination after the convulsive seizure, found a blood pressure at $140 / 90 \mathrm{mmhg}$ for the right arm and $130 / 90 \mathrm{mmhg}$ for the left arm and a heart rate of 86 beats/minute, a patient obsessed with a Glasgow score of 12/15 (eye opening 3, verbal response 4, motor response 5), bilateral pyramidal syndrome. The CT scan performed without contrast medium injection reveals multifocal intra-parenchymal hematomas with no mass effect on bilateral, temporal and frontal lobe structures associated with subdural hematoma (Figure 1 \& Figure 2).

The biological assessment, namely (Table 1): the assessment of coagulation,

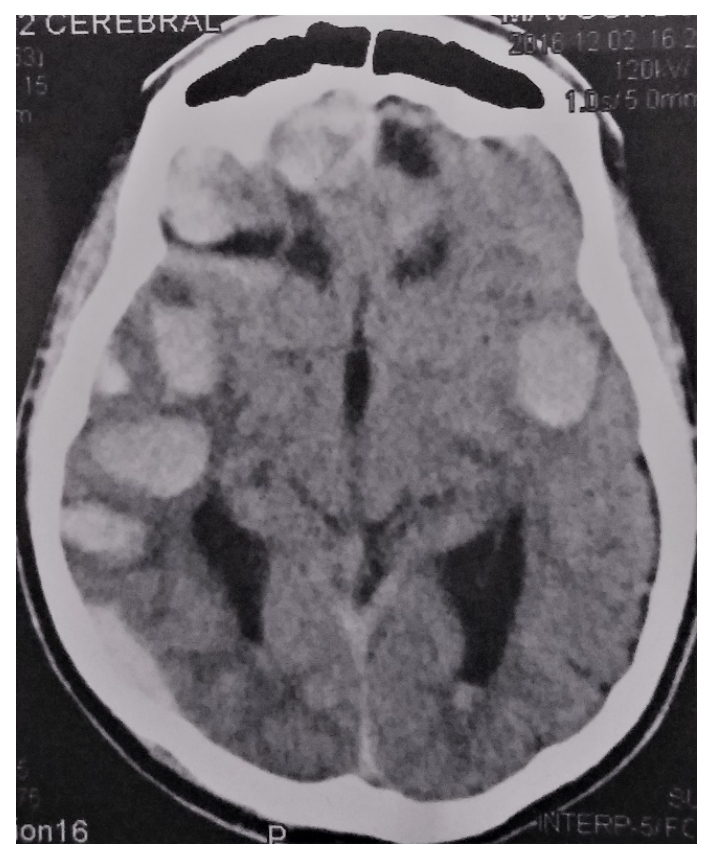

Figure 1. Brain CT scan without contrast medium injection in axial section showing multiple temporal and bilateral frontal spontaneous hyperdense hematomas and right dural hematoma not defining mass syndrome. 


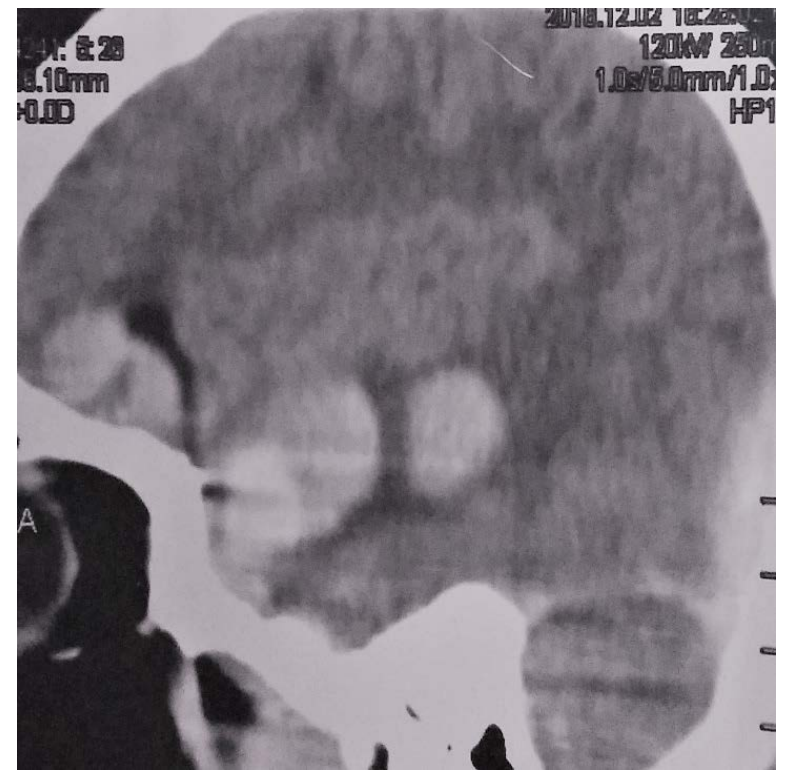

Figure 2. Brain scan in sagittal section showing spontaneous hyperdense temporo-frontal hematomas.

Table 1. Summary of the biological assessment.

\begin{tabular}{|c|c|c|}
\hline Biological tests & Résults & Normal values \\
\hline \multicolumn{3}{|l|}{ Blood count } \\
\hline - $\mathrm{GB}$ & $9.410^{3} / \mathrm{mm}^{3}$ & $3.5-1010^{3} / \mathrm{mm}^{3}$ \\
\hline - $\mathrm{Hb}$ & $14.2 \mathrm{~g} / \mathrm{dl}$ & $11-16.5 \mathrm{~g} / \mathrm{dl}$ \\
\hline - Pla & $22510^{3} / \mathrm{mm}^{3}$ & $150-39010^{3} / \mathrm{mm}^{3}$ \\
\hline \multicolumn{3}{|l|}{ Coagulation balance } \\
\hline - $\mathrm{TP}$ & $80 \%$ & $80-100 \%$ \\
\hline - TCA & $26 \mathrm{sec}$ & $24-41 \mathrm{sec}$ \\
\hline - TS & $5 \mathrm{~min}$ & $3-6 \min$ \\
\hline - Fibrinogen & $2 \mathrm{~g} / \mathrm{l}$ & $2-4 \mathrm{~g} / 1$ \\
\hline C-reactive protein & $<6 \mathrm{mg} / \mathrm{l}$ & $<6 \mathrm{mg} / \mathrm{l}$ \\
\hline Blood sugar & $0.96 \mathrm{~g} / \mathrm{l}$ & $0.60-1.10 \mathrm{~g} / \mathrm{l}$ \\
\hline Creatinine & $8 \mathrm{mg} / \mathrm{l}$ & $6-13 \mathrm{mg} / \mathrm{l}$ \\
\hline Urea & $0.45 \mathrm{~g} / \mathrm{l}$ & $0.45-1.15 \mathrm{~g} / \mathrm{l}$ \\
\hline HIV 1 and HIV 2 serology & negatif & \\
\hline \multicolumn{3}{|l|}{ Transaminases } \\
\hline - SGOT & $13.2 \mathrm{U} / 1$ & $<30 \mathrm{U} / 1$ \\
\hline - SGPT & $21.3 \mathrm{U} / 1$ & $<35 \mathrm{U} / 1$ \\
\hline \multicolumn{3}{|l|}{ Serum electrolytes } \\
\hline - Sodium & $137.2 \mathrm{mmol} / \mathrm{l}$ & $135-150 \mathrm{mmol} / \mathrm{l}$ \\
\hline - Potassium & $4.70 \mathrm{mmol} / \mathrm{l}$ & $3.5-5.5 \mathrm{mmol} / \mathrm{l}$ \\
\hline - Chlore & $101.2 \mathrm{mmol} / \mathrm{l}$ & $98-108 \mathrm{mmol} / \mathrm{l}$ \\
\hline
\end{tabular}

C-reactive protein, blood count, anti-HIV1 and anti-HIV2 antibodies, returned to normal; as well as blood glucose, blood ionogram, liver and kidney function. The management was symptomatic, namely an osmotic diuretic (mannitol), car- 
bamazepine 10 - $15 \mathrm{mg} / \mathrm{kg} /$ day in two doses; paracetamol at $3 \mathrm{~g} / \mathrm{d}$, physical rehabilitation. The evolution is marked by the recovery of consciousness with a cooperating patient, performing simple orders and a blood pressure of 120/70 mmhg at both arms, the heart rate at 68 beats/minute. He went out on the 17th day of his hospitalization. Follow-up appointments with follow-up imaging were scheduled at 1 and 3 months, but the patient was lost to follow-up.

\section{Discussion}

Spontaneous multifocal intracerebral hemorrhages are very rare events and little described in the literature [1] [6] [9]. They were seen in only $2 \%$ of hemorrhagic strokes. Their incidence is very variable from $0.7 \%$ to $3.4 \%$ of all cerebral hemorrhages [1]. Yen et al. [7] an incidence of $0.8 \%$ of multifocal intracerebral hemorrhages among all intracranial hemorrhages. In sub-Saharan Africa we have not found any publications made on this subject.

Due to the small number of reported cases, the underlying pathology is still unknown. The factors incriminated at the origin of the development of atraumatic multifocal intracerebral hemorrhage are numerous, only hypertension is responsible for at least half of spontaneous hemorrhages [10] [11]. Other factors also play a role, namely: Cerebral amyloid angiopathy, vasculitis, administration of tissue plasminogen activator by intravenous route, deep cerebral venous thrombosis, taking anticoagulant, etc. These causative factors are similar to those of focal intracerebral hemorrhages [1] [5] [11].

High blood pressure has been reported as a major risk factor for multifocal hemorrhage in several studies [6] [9]. Chronic hypertension can lead to structural and functional hemodynamic changes in the cerebral arteries [12] and lead to vascular degeneration responsible for the formation of microaneurysms, which can lead to the occurrence of multiple simultaneous hemorrhages [5] [12] [13]. However, hypertension does not seem to be the only cause, indeed multifocal intracerebral hemorrhages not associated with high blood pressure or any other degenerative cerebrovascular disease have been found, which suggests the presence of an unrecognized process involving several small cerebral arteries [14]. In the brain, a prolonged increase in cerebral perfusion affects the small perforating arteries and gradually this results in arteriopathy. This fibrinoid degeneration and lipohyalinosis weakens over time, and Charcot-Bouchard type microaneurysms develop. The sudden rupture of the latter marks the development of intracerebral hemorrhage [4] [14] [15]. These pathological changes are observed mainly in the small perforating arteries which branch out from the major intracerebral pathways with the vessel [8]. According to Weisberg et al. [16], the site of the most common non-traumatic hypertensive hemorrhages are: putamen (which represent $50 \%$ of all cases); the white matter of the temporal lobe, the frontal or parietal lobe; the thalamus; the cerebellar hemispheres. Our patient developed two hemispherical hemorrhages in the temporal and frontal lobes. 
Cerebral amyloid angiopathy in elderly patients accounts for 5\% - 20\% of recurrent or multifocal intracerebral hemorrhages [5] [11]. It is a risk factor for focal spontaneous intracerebral hemorrhage, which is associated with lobar hematomas. Amyloid protein is rarely deposited in the basal ganglia and brainstem, which are sites commonly associated with intracerebral hemorrhage linked to hypertension [11]. However, it is exceptional to find a sporadic amyloid angiopathy, responsible for a hemorrhage in a young subject like our case.

Another risk factor contributing to the occurrence of multifocal intracerebral hemorrhages is central nervous system (CNS) vasculitis. However, a normal inflammatory assessment or a normal brain biopsy does not exclude vasculitis [1] [11]. Indeed, Seo et al. [6] reported two cases of multiple intracerebral hemorrhage with a blood count and normal coagulation results but associated with an increase in the rate of sedimentation. Noskin et al. [17] have demonstrated that there is a high false negative rate of brain biopsies in the diagnosis of CNS vasculitis. In our case, no specific causal factor was found, so we consider that these intracerebral hemorrhages were spontaneous. This observation was also made by José et al. [18].

The clinical manifestations of multifocal intracerebral hemorrhages are not specific and generally depend on the side and location of the hemorrhage. Patients present with various symptoms, such as confusional syndrome, motor deficits, neuropsychological deficits, language disorders, seizures. Prognostic factors have not been reported. However, some patients have a worse prognosis than patients with isolated intracerebral hemorrhage. The neurological sequelae are serious even if the lesions are small, due to the decrease in cerebral blood flow in the two cerebral hemispheres [9].

The association of intra-parenchymal hematomas with a subdural hematoma would have evoked certain etiologies such as a hematological or oncological disease, taking toxic drugs or a HELLP syndrome, but the patient could not benefit from a complete assessment looking for these different etiologies [19].

Therapeutically no consensus has been reached due to the lack of data regarding the causal factors involved at present. The treatment depends on the reference centers. It can include a medical component only or a surgical component. The surgical removal of multifocal intracerebral hemorrhages is controversial, but Shiomi et al. [20] have suggested that Surgical treatment of multiple hematomas should be determined by the location of the hematoma. For single spontaneous intracerebral hemorrhage, surgical removal of large hematomas may be the best course of action; However, conclusive data are not available [8]. Early surgical evacuation of hemorrhages in the posterior cerebral fossa greater than $3 \mathrm{~cm}$ in diameter is indicated in case of clinical deterioration and signs of compression of the brainstem [18]. Mendelow et al. [21] revealed that early surgical treatment had no advantage over medical treatment in 1033 patients with deep multifocal intracerebral hemorrhage performed in 83 centers; However, patients with superficial hemorrhage (defined as less than $1 \mathrm{~cm}$ from the cortex) 
have shown better results when treated surgically, compared to deep localizations.

On the medical level, management is essentially based on the control of high blood pressure [22]. It is currently recommended that blood pressure be lowered below 140/90 $\mathrm{mm} \mathrm{Hg}$ within one hour of admission [23] [24]. Intracranial hypertension is treated first with an elevation of the head of the bed to 30 degrees, analgesia and sedation; Osmotic diuretics such as mannitol and hypertonic saline may be used, in addition to drainage of the CSF by ventriculostomy [21]. Simultaneous monitoring of blood pressure and intracranial hypertension can be done to ensure target cerebral perfusion pressure greater than $70 \mathrm{mmHg}$ to reduce reflex vasodilation or cerebral ischemia [25].

The use of procoagulants is not recommended unless the patient has a known coagulopathy, such as hemophilia [1] [21]. Studies have shown an increased risk of acute epileptic seizures and later epilepsy in patients with intracerebral hemorrhage [1] [5]. Acute attacks should be treated with antiepileptic drugs; However, prophylactic anticonvulsant therapy is not recommended due to lack of sufficient evidence [22]. For suspected CNS vasculitis, Noskin et al. [17] treated patients with clinical worsening with prednisone and cyclophosphamide with significant improvement. We consulted with the neurosurgery team who declined any form of surgery, so our patient only received medical treatment.

\section{Conclusion}

Spontaneous atraumatic multifocal intracerebral hemorrhage remains a very rare entity. The site of the hematoma is generally located at the level of the central gray nuclei due to chronic hypertension, however other topographies can be observed. The clinical symptoms depend on the site of the hemorrhage. The pathological mechanism and predisposing factors are still unknown. Hypertension, cerebral amyloid angiopathy and vasculitis may be responsible for his bleeding. There is no consensus on therapeutic management, which is essentially based on medical treatment; careful surgical management may be considered in the event of worsening of symptoms.

\section{Publication}

The patient agrees for the publication of this work.

\section{Conflicts of Interest}

There was no conflict of interest during our work.

\section{References}

[1] Fetcko, K.M., Hendricks, B.K., Scott, J. and Cohen-Gado, A.A. (2016) Atraumatic Multifocal Intracerebral Hemorrhage. Journal of Clinical Neuroscience, 70, 1-10. https://doi.org/10.1016/j.jocn.2016.03.009

[2] Gage, B.F., Yan, Y., Milligan, P.E., Waterman, A.D., Culverhouse, R., Rich, M.W., et 
al. (2006) Clinical Classification Schemes for Predicting Hemorrhage: Results from the National Registry of Atrial Fibrillation (NRAF). American Heart Journal, 151, 713-719. https://doi.org/10.1016/j.ahj.2005.04.017

[3] Adoukonou, T.A., Vallat, J.M., Joubert, J., Macian, F., Kabore, R., Magy, L., et al. (2010) Prise en charge des accidents vasculaires cérébraux en Afrique subsaharienne. Revue Neurologique, 166, 882-893.

https://doi.org/10.1016/j.neurol.2010.06.004

[4] Ossou-Nguiet, P.M., Ellenga-Mbolla, B.F., Odzebz, A.S.W., Otiobanda, G.F., Gankama, T.N., Obondzo Aloba, K. and Gombet, T.R. (2013) Impact of Urinary Tract and Pulmonary Infection on Mortality after Intracerebral Hemorrhage in Brazzaville. World Journal of Neurosciences, 3, 246-249. https://doi.org/10.4236/wjns.2013.34033

[5] Wu, T.Y., Yassi, N., Shah, D.G., Ma, M., Sharma, G., Putaala, J., et al. (2017) Simultaneous Multiple Intracerebral Hemorrhages (SMICH). Stroke, 48, 581-586. https://doi.org/10.1161/STROKEAHA.116.015186

[6] Seo, J.S., Nam, T.K., Kwon, J.T. and Park, Y.-S. (2014) Multiple Spontaneous Simultaneous Intracerebral Hemorrhages. Journal of Cerebrovascular and Endovascular Neurosurgery, 16, 104-111. https://doi.org/10.7461/jcen.2014.16.2.104

[7] Sampath Kumar, N.S., Neeraja, V., Raju, C.G., Padala, R.K. and Kumar, T.A. (2015) Multiple Spontaneous Hypertensive Intracerebral Hemorrhages. Journal of Stroke \& Cerebrovascular Diseases, 24, e25-e27. https://doi.org/10.1016/j.jstrokecerebrovasdis.2014.08.008

[8] Yen, C.P., Lin, C.L., Kwan, A.L., Lieu, A.S., Hwang, S.L., Lin, C.N. and Howng, S.L. (2005) Simultaneous Multiple Hypertensive Intracerebral Haemorrhages. Acta Neurochirurgica, 147, 393-399. https://doi.org/10.1007/s00701-004-0433-y

[9] Mauriño, J., Saposnik, G., Lepera, S., Rey, R.C. and Sica, R.E. (2001) Multiple Simultaneous Intracerebral Hemorrhages: Clinical Features and Outcome. Archives of Neurology, 58, 629-632. https://doi.org/10.1001/archneur.58.4.629

[10] Takeuchi, S., Takasato, Y., Masaoka, H., Hayakawa, T., Yatsushige, H. and Sugawara, T. (2011) Simultaneous Multiple Hypertensive Intracranial Hemorrhages. Journal of Clinical Neuroscience, 18, 1215-1218. https://doi.org/10.1016/j.jocn.2011.01.020

[11] Meretoja, A., Strbian, D., Putaala, J., Curtze, S., Haapaniemi, E., Mustanoja, S., et al. (2012) SMASH-U: A Proposal for Etiologic Classification of Intracerebral Hemorrhage. Stroke, 43, 2592-2597. https://doi.org/10.1161/STROKEAHA.112.661603

[12] Paulson, O.B., Waldemar, G., Schmidt, J.F. and Strandgaard, S. (1989) Cerebral Circulation under Normal and Pathologic Conditions. The American Journal of Cardiology, 63, 2c-5c. https://doi.org/10.1016/0002-9149(89)90396-2

[13] Chen, Y., Hénon, H., Bombois, S., Pasquier, F. and Cordonnier, C. (2016) Multiple Simultaneous Spontaneous Intracerebral Hemorrhages: A Rare Entity. Cerebrovascular Diseases, 41, 74-79. https://doi.org/10.1159/000442475

[14] Laiwattana, D., Sangsawang, B. and Sangsawang, N. (2014) Primary Multiple Simultaneous Intracerebral Hemorrhages between 1950 and 2013: Analysis of Data on Age, Sex and Outcome. Cerebrovascular Diseases Extra, 4, 102-114. https://doi.org/10.1159/000362111

[15] Yeh, S.J., Tang, S.C., Tsai, L.K. and Jeng, J.S. (2014) Pathogenetical Subtypes of Recurrent Intracerebral Hemorrhage: Designations by SMASH-U Classification System. Stroke, 45, 2636-2642. https://doi.org/10.1161/STROKEAHA.114.005598

[16] Weisberg, L. (1981) Multiple Spontaneous Intracerebral Hematomas: Clinical and 
Computed Tomographic Correlations. Neurology, 31, 897-900. https://doi.org/10.1212/WNL.31.7.897

[17] Noskin, O., Libman, R., Mayer, S. and Canoll, P. (2006) Multifocal Hemorrhagic Vasculopathy: Possibly a Manifestation of Central Nervous System Vasculitis. Journal of Stroke and Cerebrovascular Diseases, 15, 43-47. https://doi.org/10.1016/j.jstrokecerebrovasdis.2005.09.002

[18] Ruiz-Sandoval, J.L., Campos, A., Romero-Vargas, S., Jiménez-Rodríguez, M.I. and Chiquete, E. (2006) Multiple Simultaneous Intracerebral Hemorrhages Following Accidental Massive Lumbar Cerebrospinal Fluid Drainage: Case Report and Literature Review. Neurology India, 54, 421-424.

https://doi.org/10.4103/0028-3886.28120

[19] Coombs, J.B., Coombs, B.L. and Chin, E.J. (2014) Acute Spontaneous Subdural Hematoma in a Middle-Aged Adult: Case Report and Review of the Littérature. Journal of Emergency Medicine, 47, e63-e68. https://doi.org/10.1016/j.jemermed.2014.04.026

[20] Shiomi, N., Miyagi, T., Koga, S., Karukaya, T., Tokutomi, T. and Shigemori, M. (2004) Simultaneous Multiple Hypertensive Intracerebral Hematoma. No Shinkei Geka. Neurological Surgery, 32, 237-244.

[21] Mendelow, A.D., Gregson, B.A., Rowan, E.N., Murray, G.D., Gholkar, A. and Mitchell, P.M. (2013) Early Surgery versus Initial Conservative Treatment in Patients with Spontaneous Supratentorial Lobar Intracerebral Haematomas (STICH II): A Randomised Trial. The Lancet, 382, 397-408. https://doi.org/10.1016/S0140-6736(13)60986-1

[22] Aguilar, M.I. and Freeman, W.D. (2010) Spontaneous Intracerebral Hemorrhage. Seminars in Neurology, 30, 555-564.

[23] Anderson, C.S., Heeley, E., Huang, Y., Wang, J., Stapf, C., Delcourt, C. and Chalmers, J. (2013) Rapid Blood-Pressure Lowering in Patients with Acute Intracerebral Hemorrhage. The New England Journal of Medicine, 368, 2355-2365. https://doi.org/10.1056/NEJMoa1214609

[24] Steiner, T., Al-Shahi Salman, R., Beer, R., Christensen, H., Cordonnier, C., Csiba, L., et al. (2014) European Stroke Organisation. European Stroke Organization (ESO) Guidelines for the Management of Spontaneous Intracerebral Hemorrhage. International Journal of Stroke, 9, 840-855. https://doi.org/10.1111/ijs.12309

[25] Hemphill, J.C., Greenberg, S.M., Anderson, C.S., Becker, K., Bendok, B.R., Cushman, M., et al. (2015) Guidelines for the Management of Spontaneous Intracerebral Hemorrhage: A Guideline for Healthcare Professionals from the American Heart Association/American Stroke Association. Stroke, 46, 2032-2060. https://doi.org/10.1161/STR.0000000000000069 